\title{
Conceptualization of Online Experience
}

\author{
Sophea Chea ${ }^{1}$, Margaret M. Luo ${ }^{2}$ \\ ${ }^{1}$ Business and Information Management, Delaware Valley University, Doylestown, USA \\ ${ }^{2}$ Department of Information Management \& Institute of Healthcare Information Management, National Chung \\ Cheng University, Chiayi County, Taiwan \\ Email: sophea.chea@delval.edu, luo@mis.ccu.edu.tw
}

Received 7 April 2015; accepted 27 July 2015; published 30 July 2015

\begin{abstract}
This paper proposes a paradigm shift from online service to online experience for online service management and practices. Online experience is conceptualized. The paper further discusses the opportunities and constraints of delivering online experience.
\end{abstract}

\section{Keywords}

Online Service, Online Experience, e-Xperience, Experiential Design, Service Science

\section{Introduction}

Service is a sector of economy that accounts for most of the world's developed economy. Therefore, it is generally agreed that we are in the service economy. For example, services account for 70 percent of total US economy. Similarly, some industrial manufacturers that traditionally produce only physical products also derive larger portion of their revenues from service. For example GE uses network-enabled remote monitoring systems to service power turbines and MRI scanners for its customers. GE preemptively provides maintenance services to clients prior to any real breakdown of the machines. In doing so, GE creates value by preventing unpleasant surprise of clients from machine breakdown and thus, can charge more for the preemptive services and costs of spare parts [1]. Cleveland-based Eaton who manufactures engineered components for residential building also benefits from smart services. Eaton invents Home Heartbeat, a smart home monitoring system. Eaton builds awareness and connectivity into the components; it produces and interconnects them with the components from other companies via a wireless network to monitor the status of a home. The system is configured to text message or to email the owners about any change in the status of their houses while they are away. As a result, Eaton transforms itself from manufacturer of building components to services aggregator and manufacturer [1]. Internet pure play companies also use service strategy to achieve similar competitive advantages by bundling related service components to solve problems of their clients.

Two examples are from online trading company called $\mathrm{E}^{*}$ Trade and an online real estate broker called Redfin. $E^{*}$ Trade champions the use of web services marsh-up called Intelligent Cash Optimizer that allows customers to compare the investment of their cash in different products of $E^{*}$ Trade and to decide how they want to deploy that cash. It has gone on from cash optimizer to doing the same thing for lending products and for investing products as well. Redfin, a small real estate broker based in Seattle, combines online and offline solutions to 
provide real estate brokerage services for its clients with discount rates and use customer satisfaction to reward its brokers. As a result, the company thrives in the intensified real estate market. Although these servicing practices are not very common, they are neither random nor limited to the exemplified companies and industries; they are parts of a larger trend.

The "progression of economic value" of today's society is at the point where stand-alone service is not enough. Pine and Gilmore argue that we are now in the economy where "staging experience" for customers is the key to winning the next competitive battleground [2]. They call the present economy "experience economy"; others call it "attention economy" [3]. Forrester suggests that "experience-based differentiation" is the source of competitive advantage in the new economy. When products and services were the main foci of exchange in previous epochs, experience was the focus of exchange in today's economy. Pine and Gilmore [2] liken each business to theatrical stage, the offering to theatrical play, and the customer to guest in the theatre. The goal is to deliberately stage a personalized, memorable, and engaging experience.

Experience can be staged offline and online. Especially, due to the proliferation of e-commerce, enterprise systems, and inter-organizational systems during the last decade, staging experience online is now a reality. Furthermore, ubiquitous computing, networking, and the proliferation of microchip-embedded devices enable the experience to be staged electronically wherever the customers are. For instance, by using a combination of electronic services and traditional delivery services, FedEx creates better customer experience via a tool called MyFedEx that allows customers to track their packages, to calculate' shipping rates, to locate a store with map and driving direction and to communicate with FedEx employees [4]. The notion of experience as basis for exchange is not limited to the business world; government agencies and society at large already embrace the concepts. For example, the government of Singapore integrated the systems of 21 governmental agencies to create a one-stop business licensing portal to provide better experience for business owners [5]. US Army uses video game to entice new recruit to the experiential life of the Army.

In this paper we term online experience as experience that is staged through electronic means through either the Internet or other electronic communications. To better understand this phenomenon, we seek first to define electronic experience or online experience.

\section{Online Experience Defined}

Before getting to online experience definition we would like to present a framework of service dimensions. A service can be defined using three dimensions; level of product complexity, level of digitization, and number of providers involved in the use of the products/services. Product complexity refers to the level of technological sophistication, number of parts that form the product, duration of life cycle, and the need for maintenance. For instance, a book is not as complex as a computer. The level of digitization is the degree to which the product can be delivered via digital communication like the Internet or wireless communications. For instance, music can be regarded as digital product because it can be sent through a communication network as in the example of iTune, but it is also considered physical if it is recorded on a storage device and delivered as such. The last dimension is the number of providers involved; a product or service can be delivered entirely by one provider or by a number of providers.

We use the three-dimension framework to illustrate a case of online experience. The case that we illustrate is about a real estate brokerage start up called Redfin. Redfin's service offering is built around the concept that buyer and seller of real estate can save on commission fee with good service. Two third of the 6 percent or so of th e commission is returned to the customers. Redfin promises 100 percent satisfaction money back guarantee, and agents are given bonus for satisfying customers. What interests us here is the value proposition that Redfin is using. It is based on the online experience value proposition concept. It maximizes customer experience in every touch-point with customers. For online experience Redfin comes up with a simple and comprehensive web site that pulls data from multiple sources of information. Listing information from MLS (Multiple Listing Service) and other listing like Sell-by-owner are combined with past sales information from the counties, neighborhood information, and home price estimation from Zellow.com called Zestimate. At the beginning Redfin tried to bank on the pure play concept of real estate brokerage. However, they learn in a very painful way that personal touch does matter in the high stake business of real estate. So they added another touch-point which is the real human real estate agent. However, they still base the business proposition on experience-based differentiation by rewarding the agent that deliver 100 percent satisfaction to clients. Another effect that comes 
out of this policy is the average saving of 1 percent for customer from home price negotiation. Figure 1 presents the configuration of value components that Redfin pulls together to form better customer experience.

\section{Online Experience Business Models}

By combining the value capabilities from partners Redfin creates an online experience proposition. Note that each value capability in itself is not significant and they are the product of individual provider, but after joining them together it become significant. This can be explained from the value networks perspectives. Value network is defined as "a business design that uses digital supply chain concepts to achieve both superior customer satisfaction and company profitability. It is a fast, flexible system that is aligned with and driven by new customer choice mechanism" [6]. As a result, the value that is packed in the offering is dense in terms of amount of information, knowledge and resources. Single firm can hardly deliver such value, the key is to co-produce with business partners and a company's strategic task is the reconfiguration of its relationships and business systems. By combining several products and services Redfin can create a unique experience proposition for customers. Both home buyer and seller who use Redfin contribute to the value creation by searching online for the home themselves instead of relying on the agent alone.

Single firm with the right experience proposition can also deliver online experience alone. For instance, Second Life can deliver online experience all by itself. It bases the online experience proposition on the fantasies of many people that wish to live in alternative identities. We name Second Life's online experience model as Fantasy Fulfiller.

Another model of online experience is Solutionist which also involves one provider using the combination of online and offline value capabilities to delivers online experience. An example of a solutionist is Tesco.com, the British giant e-groceries. In 2005 it made $£ 1$ billion from online grocery. Interestingly it still secures the top spot in e-grocery market of the United Kingdom, although its delivery charges were not the cheapest. Tesco's online experience model is based on providing solution to the current brick and mortar customers who need to save time and effort in going to the store, selecting the groceries, paying and taking them back home [7]. Tesco understand that most customers don't see e-groceries as substitution for real store but they see it as a time saving solution while they still can get the products from their favorite local store with less time and efforts. Thus, Tesco integrates the online and offline experience into a single system to offer customer exceptional groceries shopping experience.

\section{Definition of Online Experience}

Online experience is electronically-enhanced combined offering of products and services to fulfill individual

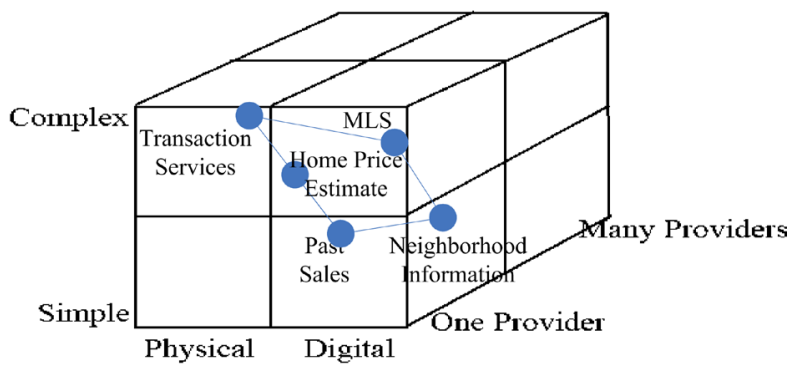

Figure 1. Components of Redfin online experience.

Table 1. From e-Service to e-Xperience.

\begin{tabular}{ccc}
\hline & e-Service & e-Xperience \\
\hline Value creation & Convenience & Meaningful Experience \\
Characteristics & Standardized \& Modular Supply Chain & Personalized \& Reconfigurable Demand Chain \\
Provider & Mostly Stand-Alone & Mostly Value Network \\
User & Client & Situated Individual \\
\hline
\end{tabular}


needs, desire, or fantasies by engaging multiple senses through appropriate touch-points.

Online experience is not static, it's existent is in the mind of individual; no two experiences are the same. Like service it is intangible, it must be consumed to experience, and it is personal. According to [8] experience is characterized by the state of flow [9], certain level of playfulness, the feeling of being in control of the situation, and also the balance between the challenge and one's own capabilities. Video game fit these characteristics well. However, we believe that online experience is not limited to gaming. If carefully planned, every information system can deliver online experience.

We would like to clarify the concept of e-service (online service). How e-service differ from online experience. Researchers from different disciplinary background define e-service differently [10] [11].

While conceptually simplistic, in practice there are some constraints in staging and delivering online experience. Some constraints are technological in nature others are managerial. There are at least four constraints to the configuration of online experience; mobility issue, coordination complexity, personalized experience, and sampling of e-experience. In this section we will discuss each of the constraints and how technologies can help us to overcome those constraints.

Mobility Issue: Most e-service and traditional services are confined to certain locations of touch point; customers need to be physically present at the point where they can access the web or service provider's kiosk to experience the service offers. For example the new experience proposition of Coldwell Banker use mapping e-service from Google in combination with its internal sales data to provide information about real estate pricing in various locations. This is a simple example of online experience. Consider this, if a company wants to propose a tour package as an online experience offer, the company must coordinate among the services of airline companies, ground transportation, traffic and weather condition information provider, and destination management companies to deliver the perfect experience to the customers. In this case the mobility issues manifest themselves stronger. For instance, the client is on his way to the airport and the plane is delayed, there must be some ways the clients can be notified about the delay and the lounge at the airport must be ready for him. This can be done in at least two ways, the message can be sent through the taxi that the client takes to notify him and/or his cell phone can receive a text message about the delay. Or better yet if the message reaches him before he left the hotel, the system can tell the taxi not to pick him up and notify him so he can allocate the time to do something else. Technological development in mobile computing and Global Positioning Systems can meet the context-aware requirement of online experience. Tesco has to deal with another issue related to mobility because Tesco's customers access the site from variety of new device such as PDAs and Digital Televisions and it also

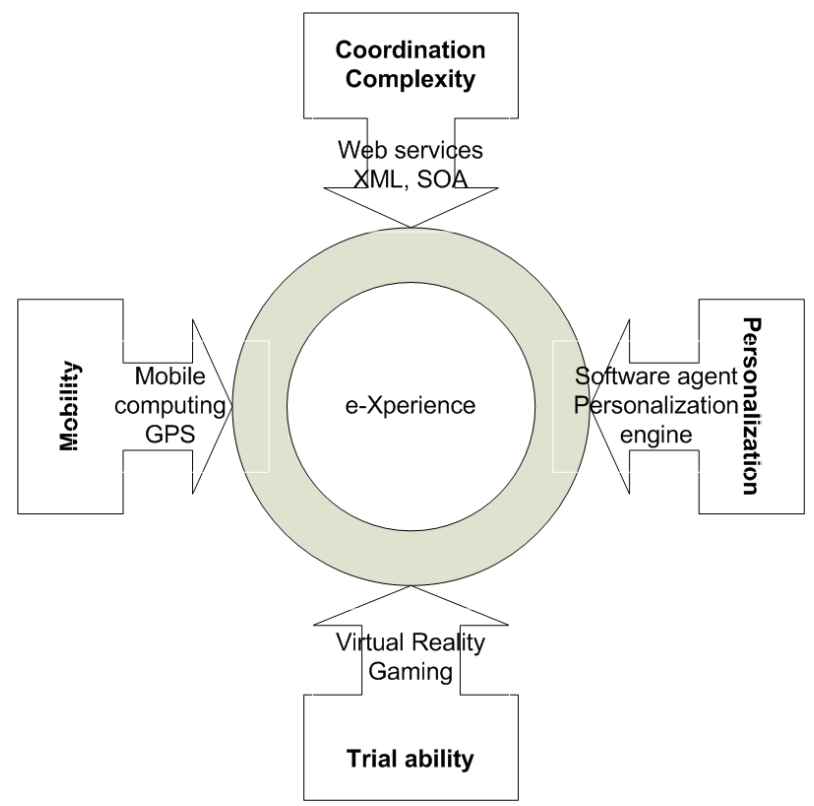

Figure 2. Constraints of e-Xpereience Configuration. Note: online experience is abbreviated as e-Xperience in this diagram. 
provide support for partially-sighted customer. However, Tesco's case is less an issue of mobility it is an issue of access because Tesco's business model does not require to serve the customers en-route. As long as they can access the site it is fine.

Coordination Complexity: Most online experience offerings are made possible by combining the value capabilities of various providers. In the case of tour package above, the offer involves the airline companies, the hotel, the taxi, and the destination management companies who organize some activities at the destination. In the traditional service settings a great deal of coordination complexities present. Any change or delay presents a great hassle to the parties involved. However, in today's networked world the flow of information is fast and the backend systems of all parties involved are integrated seamlessly enabling by the web services technologies, Service Oriented Architecture, and industry data standardization standards like XML. Web service is a self-describing, self-contained, modular application accessible over the Web. It exposes an XML interface to communicate with other Web services that is registered in the Web service registry. This technology is promising for solving coordination complexity because of the use of standard protocol and standard definition. However, managerial coordination and resource planning are still the issues for online experience partners that need to be solved. Recently, the practice of software mash up and its popularity can be a new tool for overcoming coordination complexity while implementing online experience on across connected devices. However, other issues like security and availability of information from mash up partners still need to be solved.

Personalization Issue: To achieve it intended impact online experience offer must be personalized for individual customer. Some issues related to the personalization arise. How do firm have a complete picture of individual customer while she cares about her privacy. Trust in allowing online experience provider to collect, store, and manipulate data on customer preference is important. This issue is both managerial and technological. Remember that customer is also a part of online experience, because the experience exists only in the mind of the customer. Asking for too much important can spoil the experience while not knowing the customer at all might make personalization fail. Research result show that customer is more likely to reveal personalized information if they trust the firm that they are dealing with [12]. However, state-aware software agent can help provide feedback on the state of customer during experience consumption, dynamic Web services can take care of compositing and negotiating the e-services that serve customer experience in real time. Another managerial issue related to personalization is to have complete picture of each customer. For instance, gift buying and buying for self are different. Result from previous studies showed that the personalization strategies that work are those that incorporate multiple methods/channels for different customers and web visiting scenarios [13].

Sampling Issues: Like in traditional theatrical play customer can experience the play only when they come to the theatre to watch the play and each play has to be consumed to experience it. Online experience is a personalized experience; each of the customers will experience it differently. This poses the issue of how to effectively provide sample for the customer. The emerging of visualization technologies like 3-D computing, gigapixel imaging, virtual reality, biometrics, and gaming open the opportunities for experiential sampling. For instance, U.S. Army use games to let potential recruit to sample Army experience. Amazon.com provides sampling by opening its service contents to partners in a form of Web services.

All in all, there are both managerial and technological constraints in successful delivering of online experience. Fortunately, recent technological development in CRM, inter-organizational system, Web service and agent-based context-aware technologies can help experience provider to overcome the constraints in delivering the online experience offerings.

\section{Conclusions}

This paper proposes a paradigm shift from e-service to online experience for research and practice. We contend that the age of online experience has arrived. Technological readiness is also in place to make online experience possible. Online experience is where the future of world economy is. Imagine many products and services are now outsourced to providers abroad. One good way to differentiate and stay competitive in the world stage is to innovate in online experience offerings. We proposed a framework for practitioners to understand online experience.

We believe that online experience is a promising and lasting phenomenon for the new economy. Furthermore, online experience is interdisciplinary in nature, and thus understanding it demands collaborative efforts of scientists from different disciplines, and behavioral scientists, computer scientists and systems scientists. Researchers 
who are properly positioned to explore online experience should have multi-disciplinary background. Adopting online experience paradigm leads to the research that puts individuals and tasks in the center instead of products and technologies.

\section{References}

[1] Allmendinger, G. and Lombreglia, R. (2005) Four Strategies for the Age of Smart Services. Harvard Business Review, 76, 131-145.

[2] Pine, B.J. and Gilemore, J.H. (1998) Welcome to the Experience Economy. Harvard Business Review, 76, 97-105.

[3] Davenport, T.H. and Beck, J.C. (2001) The Attention Economy: Understanding the New Currency of Business. Harvard Business School Press.

[4] Song, H. (2003) E-Service at FedEx. Communication of the ACM, 46, $45-46$.

[5] Pelly, K. and Sia, S. (2006) Challenges in Delivering Cross-Agency Integrated E-Services: The OBLS Project. Proceedings of the Twenty-Seventh International Conference on Information Systems, Milwaukee, Wisconsin, December, 1663-1680.

[6] Bovet, D. and Martha, J. (2000) From Supply Chain to Value Net. Journal of Business Strategy, 21, 24-28.

[7] Seybold, P. (2001) Get inside the Lives of Your Customers. Harvard Business Review, 79, 81-89.

[8] Boswijk, A., Thijssen, J.P.T. and Peelen, E. (2005) A New Perspective on the Experience Economy: Meaningful Experiences. Pearson Education, Amsterdam.

[9] Csikszentmihalyi, M. (1990) The Psychology of Optimal Experience. Harper Perennial, New York.

[10] Baida, Z., Gordijn, J. and Omelayenko, B. (2004) A Shared Service Terminology for Online Service Provisioning. In: Janssen, M., Sol, H.G. and Wagenaar, R.W., Eds., Proceedings of the Sixth International Conference on Electronic Commerce, 1-10. http://dx.doi.org/10.1145/1052220.1052222

[11] Stafford, T.F. (2003) E-Services. Communication of the ACM, 46, 27-28.

[12] Chellappa, R. and Sin, R.G. (2005) Personalization versus Privacy: An Empirical Examination of the Online Consumer's Dilemma. Information Technology and Management, 6, 181-202.

[13] Kazienko, P. and Kolodziejski, P. (2006) Personalized Integration of Recommendation Methods for E-commerce. International Journal of Computer Science \& Applications, 3, 12-26. 